\title{
Children as Robot Designers
}

\author{
Patrícia Alves-Oliveira \\ patri@uw.edu \\ University of Washington \\ Seattle, WA, USA \\ Ana Paiva \\ ana.paiva@inesc-id.pt
}

INESC-ID, University of Lisbon, and Radcliffe Institute for Advanced Study, Harvard University

Lisbon, Portugal, and Cambridge, MA, USA

\author{
Patrícia Arriaga \\ patricia.arriaga@iscte-iul.pt \\ Iscte-iul \\ Lisbon, Portugal
}

Guy Hoffman

hoffman@cornell.edu

Cornell University

Ithaca, NY, USA

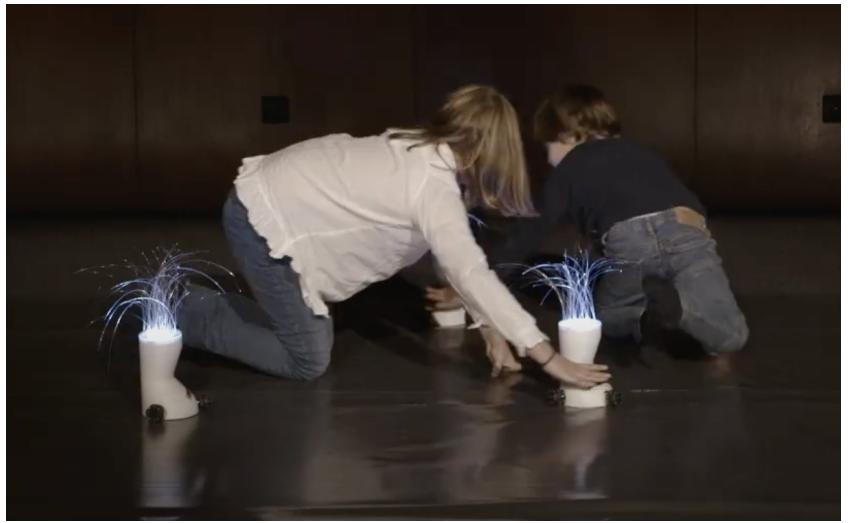

Figure 1: Creative storytelling play between children and YOLO robots.

\section{INTRODUCTION}

Children are avid adopters of technology and use technological tools in educational settings as well as during play [1,2]. Novel interactive technologies, such as social robots, bring new potential for children's learning, growing, and playing [3]. In this paper, we detail the process of designing a social robot for and with children, honoring human-centered design practices. The final goal for this robot is to stimulate the creative abilities of children during play.

Adopting human-centered practices for interactive technology designs gives voice to human needs, capabilities, and behaviors. This can lead to increased usability and value of products [4]. That said, designers of social robots are often hard-pressed to include users in meaningful ways in the design process, but end up bringing them only in later stages of evaluation, when most of the design choices have been implemented with no space for major changes. The reasons behind this approach are numerous, including (1) the need for multidisciplinary teams to work together through a long iterative process, (2) a hard-to-strike balance between engineering development and user experience research, (3) and the difficulty in finding representative participants for human-centered design of robots, e.g., such as the case of children or populations with special needs $[5,6]$. 


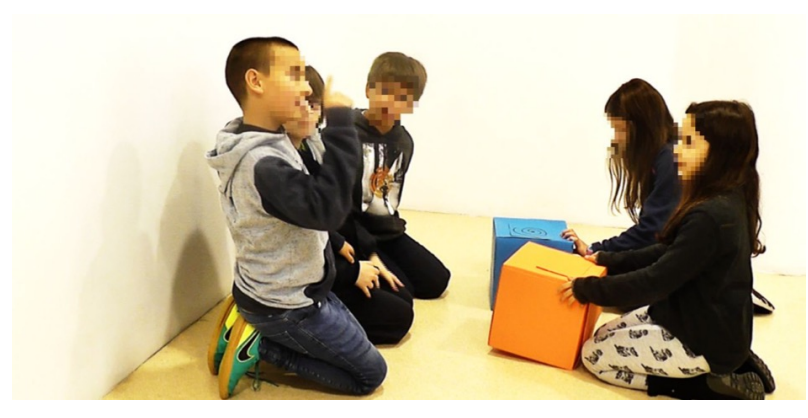

Figure 2: Children using cube-toys as stand-ins for group storytelling creation during a free play activity. This study was part of the observation of children's playful behavior described in Section 4.1 in which groups of children used the cube-toys as their characters during stories.

When focusing on children, there are additional challenges in finding human-centered methods that account for their developmental stage and empower their expressive and communicative abilities throughout the design process. For example, traditional media, such as interviews and questionnaires, are usually not the best approach with children [7].

\subsection{Contribution}

The main contribution of this work is the development of methods and tools for child-centered design of a social robot, based on adult-centered design. This resulted in a child-centered process that used methods and tools that empowered children's voices in the design of social robots. We rested our design on several identified design guidelines that made the design process successful: object choice, playfulness, child spaces, and child policies. We used objects appropriated to children, such as toys and craft materials, to create our design tools. Playfulness was at the core of all activities to stimulate children's expression and communication. Familiar spaces, such as school playgrounds and schoolyards, were the stage where the design process unfolded. Child policies related to ethical, legal, and administrative aspects, were considered from the beginning as influential factors for methods and tools choice during studies. Our child-centered design practices proved to be efficient in delivering a robot that can stimulate creativity in children during play-times, demonstrating the success criteria of our project. This design process also empowered children in making design choices for a robot that is meant to be used by them.

The resulting design is of a small non-anthropomorphic robotic toy named YOLO (Your Own Living Object) that uses movement and lights as expressive channels and has an affordance to be grabbed and moved around by children while they play [11,12]. According to the movement generated by children while grabbing the robot, YOLO can provide new ideas for their stories. It does so by using holonomic movement. With movement, the robot can either imitate the previous movement made by children thus elaborating on a given story-line (convergent thinking stimulation); or can perform a different movement, setting an intention to change the course of the story (divergent thinking stimulation). This motivates children

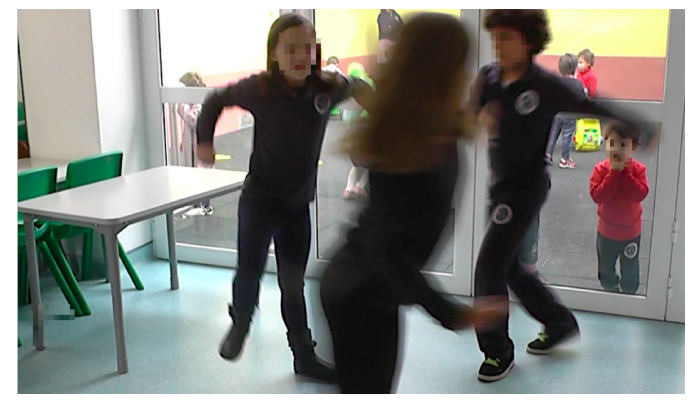

Figure 3: During the body-storming session, children were instructed to express personalities using only their bodies, refraining from using words. This primed them to use motion to illustrate their ideas. For example, they enacted personality traits, such as "grumpy", as can be seen in the figure. This was part of the co-design study detailed in Section 4.2.

to consider the robot's ideas in their stories, stimulating creative abilities. An illustration of the interaction can be seen in Figure 1 .

This report is on a two-year-long field design research, involving 142 children, and adopting a multidisciplinary approach in which a team of psychologists, computer scientists, mechanical and electrical engineers work together. We detail on the methods, tools, and guidelines for designing a social robot with children. We conclude that our design approach was successful as our results showed that the robot YOLO indeed stimulated creativity in children during playtimes.

\section{BACKGROUND}

In this Section, we review the literature on existing robots for children, the design process of robots, and the roles children take during participatory design.

\subsection{Robots and Children}

Research on social robotics for children can be divided into three major design categories: (1) off-the-shelf robots, (2) robotic design kits, (3) and robots that emerge from design research. Off-the-shelf robots are used as pre-designed research platforms (often designed by and for adults) that can be programmed for a particular research goal. Examples of commercial robots used with children are NAO [13] and Pepper [14], Jibo [15], Cozmo [16], Zeno [17], KASPAR [18], Keepon [19, 20], etc.

Robotic design kits are used as tools to foster learning in different knowledge domains. This category falls into "digital manipulatives" [21], defined as computationally-enhanced versions of traditional toys for children as new tools for learning and growing [22, 23]. Examples are LEGO Mindstorms ${ }^{\circledR}$ derived from Programmable Bricks [24], Magix [25, 26], Block Jam [27], Topobo [28], Smart Tiles [29], Digital MiMs [30], Boda Blocks [31], and others [32].

Robots derived from design research included children on some edges of the design process. For example, with Shybo robot, children (and their parents) were involved from an early stage in the design process, informing the application scenario for this robot by using survey methods. In addition to this, children were also testers of the final prototype participating in field studies. Another example is the 
Table 1: Design Process of the robot according to the Double-Diamond Model of Design [8], describing the roles of children [9], study goal and type, methods and techniques used [10], and the major outcomes of the human-centered design with children.

\begin{tabular}{|c|c|c|c|c|}
\hline & STAGE I: DISCOVER $\Rightarrow$ & STAGE II: DEFINE $\Rightarrow$ & STAGE III: DEVELOP $\Rightarrow$ & STAGE IV: DELIVER \\
\hline $\begin{array}{l}\text { Children's } \\
\text { Roles }\end{array}$ & Children as informants & $\begin{array}{l}\text { Children as design part- } \\
\text { ners }\end{array}$ & Children as testers & Children as users \\
\hline Study Goal & $\begin{array}{l}\text { Investigate the emergence } \\
\text { of creativity and how it } \\
\text { can be stimulated }\end{array}$ & $\begin{array}{l}\text { Involve children in the } \\
\text { design of the social be- } \\
\text { haviors during story- } \\
\text { telling }\end{array}$ & $\begin{array}{l}\text { Improve and refine the ro- } \\
\text { bot's AI and physical shape }\end{array}$ & $\begin{array}{l}\text { Final evaluation of a creativity } \\
\text { stimulation robot for play-times }\end{array}$ \\
\hline Study Type & $\begin{array}{l}\text { - Expert interviews and } \\
\text { observation } \\
\text { - Literature review } \\
\text { - Observation }\end{array}$ & $\begin{array}{l}\text { - Co-design with chil- } \\
\text { dren }\end{array}$ & $\begin{array}{l}\text { - Refinement of the robot } \\
\text { software } \\
\text { - Refinement of the robot } \\
\text { physical embodiment }\end{array}$ & - Experimental study \\
\hline $\begin{array}{l}\text { Methods \& } \\
\text { Techniques }\end{array}$ & $\begin{array}{l}\text { - Interviews } \\
\text { - Literature review } \\
\text { - Behavioral observation }\end{array}$ & $\begin{array}{l}\text { - Sketching } \\
\text { - Puppeteering } \\
\text { - Body-storming }\end{array}$ & $\begin{array}{l}\text { - Co-discovery } \\
\text { - Direct observation } \\
\text { - Active involvement }\end{array}$ & $\begin{array}{l}\text { - Storytelling } \\
\text { - Behavior observation and } \\
\text { analysis }\end{array}$ \\
\hline Outcomes & $\begin{array}{l}\text { - Storytelling as the activ- } \\
\text { ity for creativity stimu- } \\
\text { lation } \\
\text { - Contrast and Mirror as } \\
\text { the creativity training } \\
\text { techniques for the robot } \\
\text { - Personality as the basis } \\
\text { for the robot's social be- } \\
\text { havior to increase story } \\
\text { narratives }\end{array}$ & $\begin{array}{l}\text { - Identification of be- } \\
\text { havior patterns de- } \\
\text { signed by children as } \\
\text { input for the design } \\
\text { of the robot's behav- } \\
\text { ior }\end{array}$ & $\begin{array}{l}\text { - Selection and refinement } \\
\text { of behaviors for the robot } \\
\text { to improve the software. } \\
\text { - Adaptation of the robot's } \\
\text { physical shape to chil- } \\
\text { dren's play manipulations }\end{array}$ & $\begin{array}{l}\text { - Stories created with the robot } \\
\text { were more original and thus, } \\
\text { more creative }\end{array}$ \\
\hline
\end{tabular}

involvement of children in the design process of Ranger [33] and Cellulo [34] to inform interaction patterns by using the wizard-ofoz (WoZ) technique. With Curlybot, children were invited as testers of the final technology to study learning-oriented acquisitions [35].

Despite children being included in some stages of the design process, robots designed to be used by children are still very much in the hands of adults. So far, the literature does not report any robot that has been designed, developed, and fabricated following the voices and desires of children. In this work, we address this design space.

\subsection{Design Process of Robots}

Despite the wide range of design approaches for social robots, users are not systematically included in all design stages. In the majority, users collaborate only during the evaluation stage, rarely prevailing for the entire design process [36]. Including users in the design process aligns with critical design principles intended to engage users into thinking, exploring ideas, and challenging assumptions, leading to user empowerment [37-40].

However, critical design research is scarce in human-robot interaction (HRI) and this work is one of the first to dedicate the entire design process of a robot to children by considering their ideas and views in all design stages. Additionally, most of the aforementioned methods primarily rely on professionals, such as actors [41] and dancers [42], or include adult user-populations during the design process. This leaves children with fewer opportunities to participate in the design process of a robot that is actually meant for them [10].

Our work lies on human-centered design practices for a full design process of the social robot YOLO, by systematically and directly involving children in all design stages through participatory design methods. This methodology gives children voice during the design, which is aligning with critical design principles [39].

\subsection{Participatory Design with and for Children}

Participatory design (PD) is a method from human-centered design $(\mathrm{HCD})$ that empowers users during a design process [6, 43, 44], leading to meaningful, approachable, and joyful products or experiences [4]. Most participatory design (PD) methods applied with children grew out of or built on ideas from PD for adults [10]. However, children are a different population with different needs. Particularly, children have different cognitive, motor, emotional, and communication abilities $[45,46]$, requiring adaptation of PD methods. 


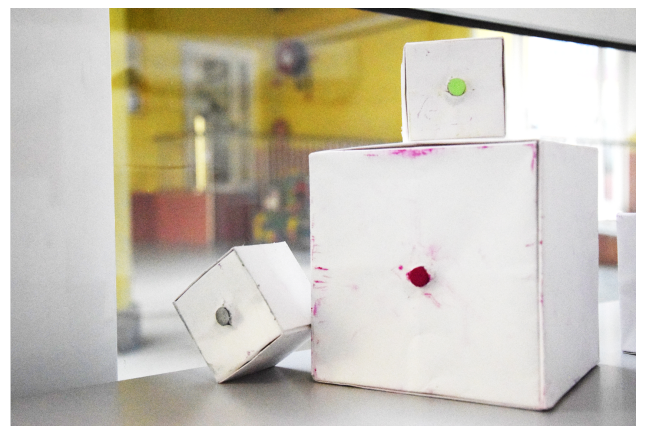

Figure 4: Paper-cubes used during the co-design study with children (Section 4.2). Fabricated with paper and including a built-in drawing mechanism, these cubes enabled: (1) children to have a visual feedback for the created motions, (2) data collection of the drawn trajectories for later implementation in the robot, (3) a constraint for children to represent the movements in a $2 \mathrm{D}$ plane and avoiding $3 \mathrm{D}$ movements that are impossible to model and replicate in a real robot.

Children can be included in PD practices under several main roles: user, tester, informant, design partner, co-researcher, and protagonist. We detail these roles below.

- Children as users use commercially available technology that has already been developed and distributed for commercial or research [9].

- Children as testers help to shape the technology but have no involvement in the design stages [9].

- Children as informants impact the design of technology from the beginning of design process [9].

- Children as partners equal stakeholders during the design process and have an enormous impact on the design and development of technologies [9].

- Children as co-researchers help sharing, gathering, and analyzing data from their practice during robot usage [47].

- Children as protagonists carry out a complete design process in which process and product reflection is a central component [48].

In our work, children were involved in different roles when designing the robot for creativity, depending on the design stage. Children took the role of design partners in the early stages of the robot conception and design, as informants and testers during design improvements, and as users when acting as participants in the validation study of the creativity intervention.

\section{DESIGN SPACE: A ROBOT FOR CREATIVITY}

Creativity is an increasingly important skill for children to have in order to thrive in adult life. Creativity is defined as the "interaction among aptitude, process, and environment by which an individual or group produces a perceptible product that is both novel and useful." [49] However, creativity has been shown to decrease in middle school age-years [50]. Research showed that creativity is an ability that can be nurtured if stimulated [51]. Despite this, classrooms generally do not appear to be creativity-fostering places, due to existing biases of traditional education practices [52-54].

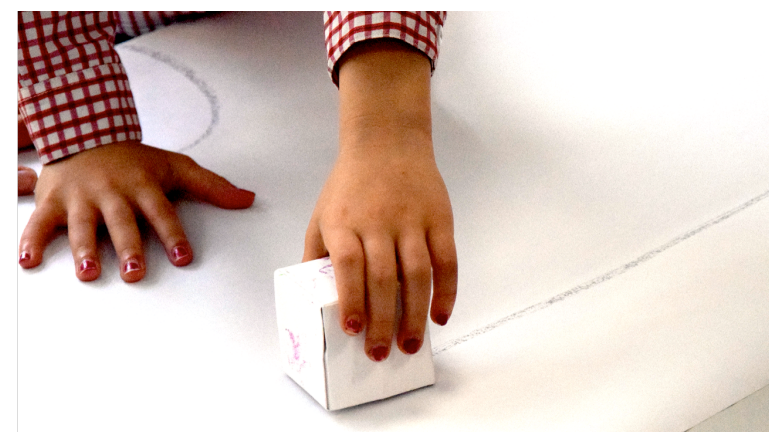

Figure 5: Example of a child expressing movement of a paper-cube by puppeteering it. This was part of the codesign study detailed in Section 4.2.

Our design challenge concerns using social robots as easy-touse-toys to be incorporated into children's spaces, such as schools, with the overarching goal of creativity development through play.

\subsection{Design Principles}

We identified a set of principles that guided the design of YOLO.

- Design Principle 1: Low Floor, Wide Walls - Technology is considered to have "low floor and wide walls" when novices find it easy to get started without require learning an entirely new skill set (low floor), and when it supports the exploration of a wide variety of projects (wide walls) [55]. This can be achieved by designing a few and specific behaviors for the robot that promote quick understanding and engagement.

- Design Principle 2: Creativity Provocation - Divergent and convergent thinking are two essential forms of creative thought [56]. Using robots to provoke higher levels of creativity requires implementing validated techniques or programs that favor these creative modes.

- Design Principle 3: Open-ended Play - "Play is the work of children" [57], as it constitutes their central daily activity used to learn, explore, and connect with the world. Openended play environments are specifically supportive of creativity as they are contexts that enable the emergence of fantasy, imagination, and make-believe [58, 59].

- Design Principle 4: Abstract Form - When expectations of social robot capabilities are not met, they tend to feel the robot let them down [60,61]. Disappointment is especially evident when interacting with anthropomorphic robots whose physical appearance does not match their social capabilities [62]. Designing for abstraction means the physical appearance of the robot does not compromise its social abilities which are instead discovered during interaction.

Building on these four principles, the robot was designed as follows: To create a low floor, we designed a robot with a limited number of features, which are simple and specific, and that enable children without any previous experience to create a story. To create wide walls, the robot behaviors were designed as non-directional, 


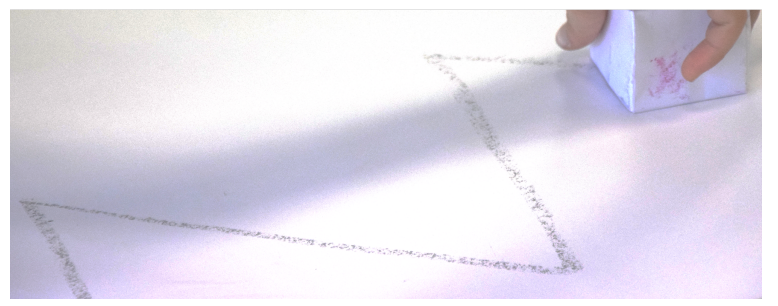

Figure 6: Example of a sketch of a child collected from puppeteering a paper-cube.

allowing for the creation of any story content. To provoke creativity, we focused on two techniques that allow for the stimulation of divergent and convergent thinking, which are used by the robot at specific stages of the storytelling; the first technique called "Mirroring" enables the elaboration of a given story idea (convergent thinking) and the other technique, called "Contrasting", moves towards a plot twist (divergent thinking). Open-ended play was supported as children were allowed to create a story about any theme they desired without time limits. To avoid disappointment, the robot was designed with physical affordances that would map its actual capabilities, and without anthropomorphic features.

\section{CHILD-CENTERED ROBOT DESIGN}

Our design approach is based on the Double-Diamond Design Process Model [4, 8], which maps HCD onto four stages: Discover, Define, Develop, and Deliver. Table 1 shows how children's design roles map onto the established Double-Diamond Design Process Model, and how it relates to the various research activities undertaken as part of this project.

\subsection{Discovery with Experts, Theory, and Observation}

The first stage of the Double-Diamond Design Process is "Discover", where basic insights about the problem are collected. In our work, the goal of this stage was to investigate how creativity unfolds and what practices can be applied to stimulate it. We used a three-fold approach, which included interviews with creativity education experts, an extensive literature review of theories of creativity, and direct observation of children during playtime. At this stage, children were included as informants.

Expert Interviews and Observations - We conducted semistructured interviews and direct observation of two creativity education experts that provide dance and theatre improvisation classes to children. Our goal was to understand the methods they use to stimulate creativity during these activities. We discovered that creativity occurs through structured but open-ended activities framed with playfulness [63]. One aspect that was considered common in every creative activity was the emergence of stories that framed the creations with children. The major outcome from this stage was to choose a storytelling activity as the creative context for the robot.

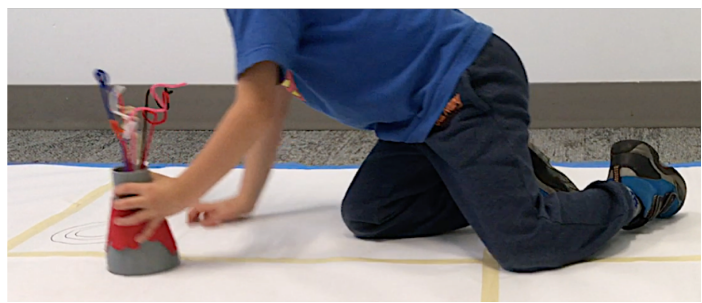

Figure 7: Manipulation of a robot prototype for the study of the size of the robot and children's grasping behavior. The robot is covered with red clay to collect data about where and how children hold the robot. This was part of the study of the robot physical embodiment described in Section 4.3.

Literature Review - We conducted a systematic review of validated techniques for creativity training with children [64]. This systematic review included a survey of 2247 scientific articles from 1961 to 2018, filtered down to a full analysis of 49 papers using the PRISMA method [65]. Creativity training programs in the literature were as diverse as using physical exercises related with relaxation [66], improvisation [67], pretend play [68], computerenvironments [69], and robots [70]. The most influential finding from this stage was the choice of two techniques to be implemented in the robot aimed at stimulating children's creativity during storytelling, for which the chosen techniques were "Contrasting" and "Mirroring" [71]. Both of these techniques relate to idea generation, a core aspect of story creation. While the Contrast technique stimulates divergent thinking, the Mirror technique is responsible for the development of convergent thinking. Both are required to establish the emergence of creativity [72], rather than the more basic act of unregulated self-expression [56].

Observation - We conducted a field study in a school setting using direct observation with video recordings for post-observation, to understand how small groups of children create ideas together in a storytelling context. A sample of 13 children (4 female, 7-10 yo) organized in four groups (three groups of 3 children and one group of 4) participated in this study. Cube-toys were chosen as story characters due to their abstractness and to ensure uniformity in the children's experience (see Figure 2). We observed each group for about $30 \mathrm{~min}$, with a total observation time in the school of $2 \mathrm{~h} \mathrm{[73].}$

This study provided three outcomes for the design process. The first outcome concerns the unstructured nature of storytelling play in which children oscillated between highly creative moments of divergent thinking showing thunderstorms of ideas, to convergent thinking translated by meaning-making moments where they chose which ideas were kept in their story. This supported the choice of the Contrasting and Mirroring techniques for the robot, which were initially chosen during the literature review. The second outcome concerns the difficulty of sharing the cube-toys between them during the story creation. Therefore, the number of robots and children should be even to facilitate dynamics between groups of children, informing the need to build more than one robot for group interactions. The third outcome concerns children using personality attributes in the cube-toys to create new narratives in their story. 


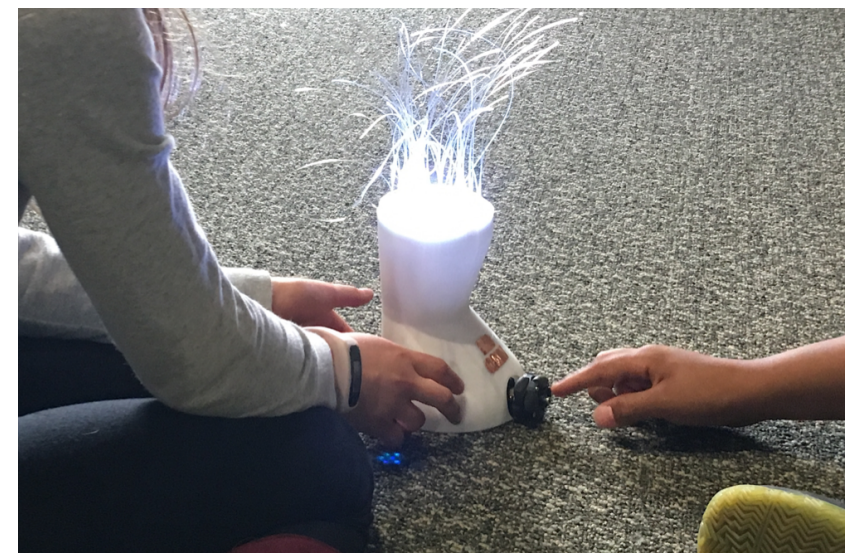

Figure 8: Children play with the robot part of the validation of social behaviors for storytelling described in Section 4.4.

This opened a design opportunity to use personality as the basis for the robot's social behavior to provoke more story-lines when children play with the robot. Creativity and personality are also known to be interconnected variables when facing a creative situation $[74,75]$.

\subsection{Definition through Body-Storming, Acting, and Drawing}

The second stage of the Double-Diamond Design Process is "Define", which focuses on specifying details of the design requirements. In our work, the goal of this stage was to translate the high-level findings from the discovery stage into specific requirements for the development of the first robot prototype. We had children as partners in the design process, adapting PD methods such as bodystorming, puppeteering, and sketching for children as co-designers. At this stage, children were included as design partners.

Co-design with Children - A study was conducted in a school with 44 children ( 25 female, 6-9 yo) participating in the design of the robot's social behaviors. Based on the previous phrase, we focused on personality traits within story-line creation. Children performed the activity in groups of $3-5$, with each session lasting 1 hour and the total time of all sessions being 13 hours [76].

During the co-design study, children played the role of co-designers by designing motion and attributing color for social expressive robot behavior. We used body-storming to prime children toward understanding personality traits. Body-storming is a form of PD to enact experiential awareness [77]. The goal of body-storming was to verify (and in some cases teach) the meaning of the different personality traits that they would represent in the robot in the following stage. Figure 3 shows children in our study engaged in bodystorming different personality types they would later imbue in the robot.

The next stage was to use puppeteering and sketching to develop and elaborate on the social behavior of the robot. We built a paper cube with a built-in drawing mechanism and asked children to act out how this cube would behave according to the personality they were creating (see Figure 4). This mechanism enabled children to represent the movements of the robot by drawing them in large paper sheets of paper (see Figure 6). We collected the resulting sketches, in addition to video and audio recordings, to support the analysis of the results (see Figure 5). We discovered that children create consistent patterns of movements according to different personality types [76]. The major outcome of this study was the generation of specific motion and color patterns, derived from children's interpretation of personalities, to implement in the social behavior of the robot.

\subsection{Development through Iterative Prototyping}

The third stage of the Double-Diamond Design Process is "Develop", the iterative development of prototypes. In our work, the goal of this stage was to develop both the artificial intelligence (AI) software and the physical embodiment of the robot. At this stage, children were included as testers of the robot.

Refinement of the Robot software - We conducted a study in a Science Museum for children to test the first iteration of interactive behaviors, using a low-fidelity mechanically actuated robot prototypes (see Figure 9-3,4) for children to play with. The total time of the study was 4 hours and a total of 20 children (7-9 yo) played with the robot freely. The robot acted autonomously, displaying a set of behaviors inspired by the co-design study, including colored lights and movements. We relied on Co-discovery and Active Intervention methods to elicit feedback from children [78]. During Co-discovery, children consult each other to understand how the robot works. In our study, children were organized into small groups and were prompted to tell each other how they were playing with the robot.

During Active Intervention the researcher asked questions about the storytelling task and also about desired behaviors that children would like to see in the robot. In addition to these techniques, we used direct observation of children freely playing with the robot to gather additional design requirements. The major outcome of this study was the selection and refinement of behaviors for the robot. For example, colors and motion were a major drive in storytelling. This result led us to explore richer ways to use these modalities by coupling light brightness and motion speed for behavior combination. We removed of some features in the robot that did not support interaction towards storytelling and creation, such as sounds that children paid little attention to compared to other features. The software for YOLO with accompanying tutorials and an API can be found in open-access in Alves-Oliveira et al. (2020) [79].

Refinement of the robot hardware - We conducted a laboratory study with 3D printed non-actuated prototypes of the robot to gather design requirements for the physical shape and size of the robot. We covered the robots' shell with clay to get data about where children place their hands to hold and manipulate the robot (see Figure 7). We used direct observation to discover the best suitable size for the robot, and to study how children grabbed the robot to inform ergonomic modifications in the shell (see Figure 9-5). A total of 3 children ( 1 female, 7 yo) participated by individually playing with different prototypes of the robot in sessions of 30 minutes. 


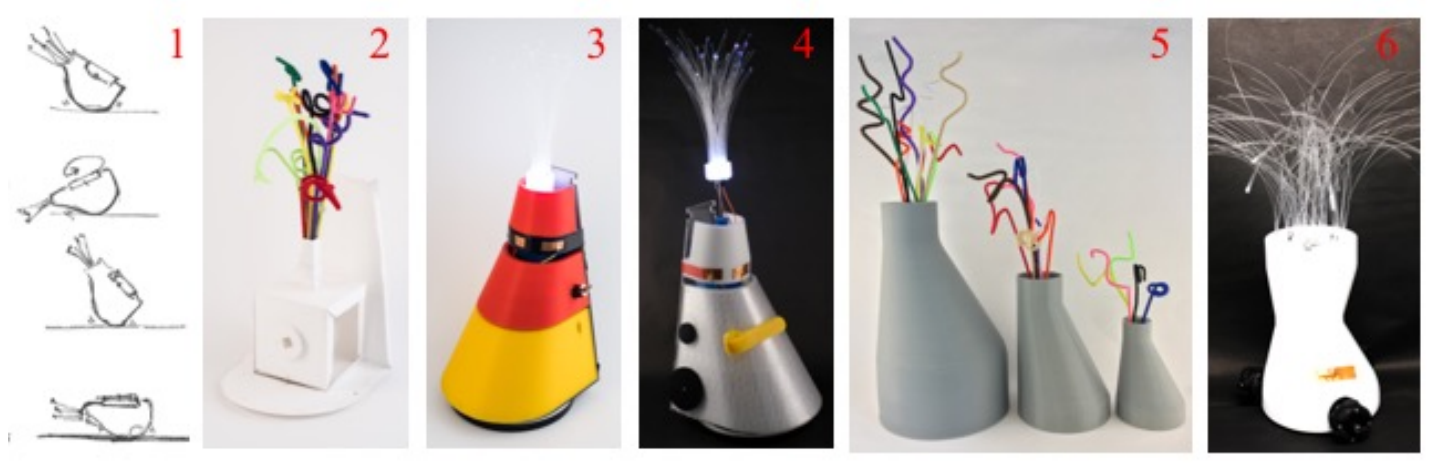

Figure 9: Iterative prototypes of the robot designed using the process described in this paper. From left to right: 1. Early sketches, 2. Paper prototype to explore scale and mechanism, 3. First actuated prototype used in the "Develop" stage; 4. Second actuated prototype used in the "Develop" stage, 5 . Three different passive robot stand-ins for scale and grasp studies; 6. Final version of the robot.

The measure of analysis used consisted of the number of instances of grabbing behavior during play. Therefore, $n=40$ instances were analyzed, revealing that: (1) children had difficulties in grasping the large-sized robot because the shell was too large, but grasped the medium-sized robot comfortably; (2) children did not treat the small-sized robot as a character during play, possibly because its small shell did not evoke agency; (3) children did not have orientation commitment when manipulating this abstract robot as they did not attribute a fixed "front" or "back" side to it; (4) children consistently used the same area on the robot for manipulating it, suggesting an ideal design space for grabbing;. Data collection ceased at an early stage due to saturation, which occurs when data keeps showing the same results no matter how many participants are recruited [80, 81]. The major outcome of this study was the commitment to a medium-sized robot with a concavity for grasping. This lead to mechanical decisions of accommodating smaller sensors and actuators that fit the reduced size model. The full guide to build YOLO with accompanying tutorials can be found in open-access in Alves-Oliveira et al. (2019) [82].

\subsection{Delivery through Testing}

The fourth and final stage of the Double-Diamond Design Process is "Deliver", where a more developed prototype is taken through testing and further refinement. We view this stage as the "Evaluation" stage as we implemented the final prototype of the robot and conducted an experimental study. At this state, children were included as users of YOLO.

The aim of our study was to test the efficacy of the robot in stimulating creativity of children. For this, we instructed children to create a story with the robot, using it as a character for their stories (see Figure 1). A total of 62 children ( 45 male) aged between 7-10 years old participated in this study. The stories created by the children with the robot were compared against the condition of creating a story with the same robot but without displaying any behaviors, and a robot turned off (see Figure 8). We analyzed the stories created by the children using the recording of their voices. Involved coders evaluated relevant variables in creativity research, such as originality, fluency, flexibility, and elaboration. According to literature, when these variables are present in a creative process, the creativity is deemed high [83-85]. Results showed that when children played with the full version of the robot, their stories were more original. More details about this study can be found in AlvesOliveira et al. (2020) [86]. Note that the paper [86] described the experimental study of children using the robot to create stories, whereas the work presented in this paper describes the design study of the conception, fabrication, and development of the robot.

\section{GUIDELINES FOR CHILD-ROBOT DESIGN}

We described a two-year-long process that adapted participatory design methods and techniques to involve children in the design process of a social robot. Throughout this work, we identified several design principles that can support the inclusion of children in the social robotic design process.

- Playfulness, a central mode of communication for children, should be at the core of all design activities. Play, especially social play, is a key part of child development [87]. Play is defined as a minimally-scripted, open-ended exploration where children are absorbed in the spontaneity of the experience [88]. According to their developmental stage, children engage in different types of play [89] such as physical, intellectual, socioand emotional- play [90], symbolic and pretend play, including playing with objects and games with rules [91]. In our work, we have imbued all design activities with playful elements to encourage children's expression during the design process of the robot. We relied on playful activities such as acting, sketching, body-storming, and traditional games, to ground the activities that invite children to the design.

- Toys and craft materials are used by children daily and should be used as tools in the design process. During childhood, children manipulate objects such as toys to explore and make sense of the world around them [92]. Toys are tools that are approachable and safe to play with, fostering the development of children. Froebel's gifts[93] and Montessori's view on "education of the senses" [94] are examples of how manipulatives can be used to empower children's growth and development. In our 
work, we have incorporated toys and materials that are part of a child's world in all design activities during the robot design and creation. To this end, we opted for paper, crayons, and cards, as the tools that children relied on for the robot design.

- Child spaces, such as playgrounds, should be the stage on which the design process unfolds. "Playscapes" are environments that are natural and in which children find joy and safety to play [95]. Research on playground designs has brought to light qualities that lead to the most playful behaviors in children [96]. Effective playspaces support a range of social scales, allowing for solitary and social play; effective playgrounds embrace emotional requirements, such as emotional relief spaces, including privacy and break away points for quiet play [97]. In our work, we have used interior school playgrounds as they evoke playfulness and put our children co-designers in the right mindset for creative exploration. Our work is based on design-research for which we have relied on theoretically-inspired methods applied to a local design problem that has the potential to impact innovations within the global field of design in HRI [98].

- Using child-appropriate protocols and materials. Consider a narrative of briefing and debriefing that children can understand to explain the goal of the research. One example for a briefing protocol is the CHECk Tool [99] commonly used during PD sessions with children [100]. This will enable ethical and informed participation of children, empowering them to decide if they want to enroll in the study. Consider data collection methods that are child-friendly, such as the Fun Toolkit that uses a Smilyometer instead of Likert scales [101]. before jumping into the actual activity add an ice-breaking activity with children that can be as simple as sharing hobbies or implementing other techniques, such as Vignettes [102]; this will result in a more relaxed environment with children being more expressive and honest in their opinions towards the technology being tested [103].

- Designing with children requires a multidisciplinary team. Experts from a variety of backgrounds are a requisite when working with children. For example, when performing a study with children in a school, an expert in children's dynamics (such as a psychologist that is trained to interact with children in study contexts) is required, as well as an expert in robotics (such as an engineer that can intervene when a problem with the robot arises). Multidisciplinary teamwork enables focus on different aspects during a study. In teams made up of experts in different backgrounds, however, special care needs to be given to develop a common language to support mutual understanding during different design stages. Team members should be trained together in the lab before heading to a study with children. should meet regularly to provide updates about design stages and make sure that their individual tasks converge toward the intended project goal.

- Prepare to spend time on legal and ethical policies that concern child studies. In particular, note that these policies are very localized and thus differ per institutions (e.g., school district, university, specific school policies). Safety standards require that the methods and materials employed in studies with children are certified or are adapted for the child's developmental stage. Privacy and confidentiality require the adoption of alternative methods for data collection that protect a child's identity. All of this can cause restrictions on the study conducted and may therefore require exploring alternatives to originally conceived methods (e.g., using direct observation instead of video recordings). Having a long preparation time, and being open to change, is key to conducting design studies with children.

- Conduct pre- and post-activities with your study partners, such as schools and museums. Visit the place where the study will be performed beforehand to understand the resources you have available, as this might define the conditions for your study. This includes understanding the physical (e.g., spaces in the school that you can use to conduct the sessions, location of power outlets, etc) and administrative conditions (e.g., understanding who you will be coordinating with to have children coming in an organized way to the sessions). Consider performing clarification sessions with teachers and parents before the study begins as a strategy to have the institution on board during your study and parents signing consent forms in an informed way. At the end of the study thank the school for the time, space, and coordination that enabled the study to be performed. This can be accomplished by performing a debriefing session about preliminary results at the end of the study, or by sending materials of interest to the school such as articles that describe your results. This is not only a way to thank your partners, but also assures a good connection to institutions and provide a return place in case additional sessions are needed.

\section{CONCLUSION}

This work shows that designing and testing technologies with children is important to develop robots that accommodate their needs and that are understandable for them. Throughout this work, we identified design guidelines that promote the successful inclusion of children in the design of robots: object choice, playfulness, child spaces, and child policies. The relied on design principles from constructionism theory and creativity research, such as low floor, wide walls, creativity provocation behavior, open-ended play, and abstract form to lead the design for this robot. We hope that the detailed description of a multi-stage design process can provide specific methods and techniques, as well as overarching principles, for future designers of social robots for children.

Despite the richness of this design process, our work comes with limitations that we would like to acknowledge. A major limitation is that we have not compared our child-centered design process to other processes of robot design. For future work, it would be interesting to compare different approaches in robot design, accounting for different levels of user engagement.

\section{ACKNOWLEDGMENTS}

This work was supported by national funds through FCT, Fundação para a Ciência e a Tecnologia under project UIDB/50021/2020 and $\mathrm{P}$. Alves-Oliveira acknowledges an FCT Grant, FRH/BD/110223/2015.

\section{REFERENCES}

[1] T. Tarpley, "Children, the internet, and other new technologies," Handbook of children and the media, pp. 547-556, 2001.

[2] S. L. Calvert, "Children as consumers: Advertising and marketing," The future of children, pp. 205-234, 2008

[3] C. L. Breazeal, Designing sociable robots. MIT press, 2004. 
[4] D. Norman, The design of everyday things: Revised and expanded edition. Constellation, 2013.

[5] L. Damodaran, "User involvement in the systems design process-a practical guide for users," Behaviour \& information technology, vol. 15, no. 6, pp. 363-377, 1996.

[6] D. Schuler and A. Namioka, Participatory design: Principles and practices. CRC Press, 1993.

[7] A. Druin, J. Stewart, D. Proft, B. Bederson, and J. Hollan, "Kidpad: a design collaboration between children, technologists, and educators," in Proceedings of the ACM SIGCHI Conference on Human factors in computing systems. ACM 1997, pp. 463-470.

[8] B. D. Council, "The design process: The 'double diamond'design process model," http://www. designcouncil. org. uk/about-design/how-designers-work/the-designprocess/. Acesso em, vol. 11, no. 12, p. 2013, 2005.

[9] A. Druin, "The role of children in the design technology," Tech. Rep., 1999.

[10] J. A. Fails, M. L. Guha, A. Druin et al., "Methods and techniques for involving children in the design of new technology for children," Foundations and Trends $₫$ in Human-Computer Interaction, vol. 6, no. 2, pp. 85-166, 2013.

[11] P. Alves-Oliveira, P. Arriaga, A. Paiva, and G. Hoffman, "Yolo-your own living object," in Companion of the 2020 ACM/IEEE International Conference on HumanRobot Interaction, 2020, pp. 638-638.

[12] P. Alves-Oliveira, A. Chandak, I. Cloutier, P. Kompella, P. Moegenburg, and A. E Bastos Pires, "Yolo - a robot that will make your creativity boom," in Companion of the 2018 ACM/IEEE International Conference on Human-Robot Interaction, 2018, pp. 335-336.

[13] P. Alves-Oliveira, P. Sequeira, F. S. Melo, G. Castellano, and A. Paiva, "Empathic robot for group learning: A field study," ACM Transactions on Human-Robot Interaction (THRI), vol. 8, no. 1, pp. 1-34, 2019.

[14] F. Tanaka, K. Isshiki, F. Takahashi, M. Uekusa, R. Sei, and K. Hayashi, "Pepper learns together with children: Development of an educational application," in Humanoid Robots (Humanoids), 2015 IEEE-RAS 15th International Conference on. IEEE, 2015, pp. 270-275.

[15] B. Scassellati, L. Boccanfuso, C.-M. Huang, M. Mademtzi, M. Qin, N. Salomons, P. Ventola, and F. Shic, "Improving social skills in children with asd using a long-term, in-home social robot," Science Robotics, vol. 3, no. 21, p. eaat7544, 2018.

[16] S. Druga, R. Williams, C. Breazeal, and M. Resnick, "Hey google is it ok if i eat you?: Initial explorations in child-agent interaction," in Proceedings of the 2017 Conference on Interaction Design and Children. ACM, 2017, pp. 595-600.

[17] D. Cameron, S. Fernando, E. Collins, A. Millings, R. Moore, A. Sharkey, V. Evers, and T. Prescott, "Presence of life-like robot expressions influences children's enjoyment of human-robot interactions in the field," in Proceedings of the AISB Convention 2015. The Society for the Study of Artificial Intelligence and Simulation of Behaviour, 2015.

[18] S. Costa, H. Lehmann, K. Dautenhahn, B. Robins, and F. Soares, "Using a humanoid robot to elicit body awareness and appropriate physical interaction in children with autism," International journal of social robotics, vol. 7, no. 2, pp. 265-278, 2015

[19] I. Leite, M. McCoy, M. Lohani, D. Ullman, N. Salomons, C. Stokes, S. Rivers, and B. Scassellati, "Emotional storytelling in the classroom: Individual versus group interaction between children and robots," in Proceedings of the Tenth Annual ACM/IEEE International Conference on Human-Robot Interaction. ACM, 2015, pp. $75-82$

[20] S. Shen, P. Slovak, and M. F. Jung, "Stop. i see a conflict happening.: A robot mediator for young children's interpersonal conflict resolution," in Proceedings of the 2018 ACM/IEEE International Conference on Human-Robot Interaction. ACM, 2018, pp. 69-77.

[21] S. Papert, Mindstorms: Children, computers, and powerful ideas. Basic Books, Inc., 1980.

[22] M. Resnick, "Technologies for lifelong kindergarten," Educational technology research and development, vol. 46, no. 4, pp. 43-55, 1998.

[23] M. Resnick, F. Martin, R. Berg, R. Borovoy, V. Colella, K. Kramer, and B. Silverman, "Digital manipulatives: new toys to think with," in Proceedings of the SIGCHI conference on Human factors in computing systems. ACM Press/Addison-Wesley Publishing Co., 1998, pp. 281-287.

[24] M. Resnick, F. Martin, R. Sargent, and B. Silverman, "Programmable bricks: Toys to think with," IBM Systems journal, vol. 35, no. 3.4, pp. 443-452, 1996.

[25] E. Ackermann, C. Strohecker, and A. Agarwala, "The magix series of playful learning environments," Paper TR97-24, MERL-Mitsubishi Electric Research Laboratory, 1997.

[26] E. Ackermann and C. Strohecker, "Build, launch, convene: Sketches for constructive-dialogic play kits," in TR99-30, Mitsubishi Electric Research Lab. Citeseer, 1999.

[27] H. Newton-Dunn, H. Nakano, and J. Gibson, "Block jam: a tangible interface for interactive music," in Proceedings of the 2003 conference on New interfaces for musical expression. National University of Singapore, 2003, pp. 170-177.

[28] H. S. Raffle, A. J. Parkes, and H. Ishii, "Topobo: a constructive assembly system with kinetic memory," in Proceedings of the SIGCHI conference on Human factors in computing systems. ACM, 2004, pp. 647-654

[29] N. Elumeze and M. Eisenberg, "Smarttiles: mobility and wireless programmability in children's construction and crafts," in Wireless and Mobile Technologies in Education, 2005. WMTE 2005. IEEE International Workshop on. IEEE, 2005, pp. $8-\mathrm{pp}$.

[30] O. Zuckerman, S. Arida, and M. Resnick, "Extending tangible interfaces for education: digital montessori-inspired manipulatives," in Proceedings of the SIGCHI conference on Human factors in computing systems. ACM, 2005, pp. 859-868.

[31] L. Buechley and M. Eisenberg, "Boda blocks: a collaborative tool for exploring tangible three-dimensional cellular automata," in Proceedings of the 8th iternational conference on Computer supported collaborative learning. International Society of the Learning Sciences, 2007, pp. 102-104.

[32] E. Schweikardt and M. D. Gross, "A brief survey of distributed computational toys," in Digital Game and Intelligent Toy Enhanced Learning, 2007. DIGITEL'07. The First IEEE International Workshop on. IEEE, 2007, pp. 57-64.

[33] J. Fink, S. Lemaignan, P. Dillenbourg, P. Rétornaz, F. Vaussard, A. Berthoud, F. Mondada, F. Wille, and K. Franinović, "Which robot behavior can motivate children to tidy up their toys?: Design and evaluation of ranger," in Proceedings of the 2014 ACM/IEEE international conference on Human-robot interaction. ACM, 2014, pp. 439-446.

[34] A. Özgür, S. Lemaignan, W. Johal, M. Beltran, M. Briod, L. Pereyre, F. Mondada, and P. Dillenbourg, "Cellulo: Versatile handheld robots for education," in Proceedings of the 2017 ACM/IEEE International Conference on Human-Robot Interaction. ACM, 2017, pp. 119-127.

[35] P. Frei, V. Su, B. Mikhak, and H. Ishii, "Curlybot: designing a new class of computational toys," in Proceedings of the SIGCHI conference on Human factors in computing systems. ACM, 2000, pp. 129-136.

[36] J. J. Jensen and M. B. Skov, "A review of research methods in children's technology design," in Proceedings of the 2005 conference on Interaction design and children. ACM, 2005, pp. 80-87.

[37] A. Dunne, "Hertzian tales: Electronic products, aesthetic experience, and critical design (mit press)," 2005

[38] S. Bardzell, J. Bardzell, J. Forlizzi, J. Zimmerman, and J. Antanitis, "Critical design and critical theory: the challenge of designing for provocation," in Proceedings of the Designing Interactive Systems Conference. ACM, 2012, pp. 288-297.

[39] J. Bardzell and S. Bardzell, "What is critical about critical design?" in Proceedings of the SIGCHI conference on human factors in computing systems. ACM, 2013, pp. 3297-3306.

[40] J. Zimmerman, J. Forlizzi, and S. Evenson, "Research through design as a method for interaction design research in hci," in Proceedings of the SIGCHI conference on Human factors in computing systems, 2007, pp. 493-502.

[41] H. Knight, "Eight lessons learned about non-verbal interactions through robot theater," in International Conference on Social Robotics. Springer, 2011, pp. $42-51$.

[42] R. Ros and Y. Demiris, "Creative dance: An approach for social interaction between robots and children," in International Workshop on Human Behavior Understanding. Springer, 2013, pp. 40-51.

[43] A. Veale, "Creative methodologies in participatory research with children," Researching children's experience: Approaches and methods, pp. 253-272, 2005.

[44] J. Simonsen and T. Robertson, Routledge international handbook of participatory design. Routledge, 2012.

[45] H. E. Gruber and J. J. Vonèche, The essential piaget. Routledge \& Kegan Paul London, 1977.

[46] R. M. Lerner, C. Theokas, and D. L. Bobek, "Concepts and theories of human development: Historical and contemporary dimensions." 2005.

[47] F. v. Doorn, M. Gielen, and P. J. Stappers, "Children as coresearchers: more than just a roleplay," in Proceedings of the 2014 conference on Interaction design and children, 2014, pp. 237-240.

[48] O. S. Iversen, R. C. Smith, and C. Dindler, "Child as protagonist: Expanding the role of children in participatory design," in Proceedings of the 2017 Conference on Interaction Design and Children, 2017, pp. 27-37.

[49] J. A. Plucker, R. A. Beghetto, and G. T. Dow, "Why isn't creativity more important to educational psychologists? potentials, pitfalls, and future directions in creativity research," Educational psychologist, vol. 39, no. 2, pp. 83-96, 2004.

[50] K. H. Kim, "The creativity crisis: The decrease in creative thinking scores on the torrance tests of creative thinking," Creativity Research fournal, vol. 23, no. 4, pp. 285-295, 2011.

[51] R. K. Sawyer, M. Csikszentmihalyi, V. John-Steiner, S. Moran, D. H. Feldman, H. Gardner, R. J. Sternberg, J. Nakamura et al., Creativity and development. Counterpoints: Cognition, Memo, 2003

[52] E. P. Torrance, "A longitudinal examination of the fourth grade slump in creativity," Gifted Child Quarterly, vol. 12, no. 4, pp. 195-199, 1968.

[53] A. Furman, "Teacher and pupil characteristics in the perception of the creativity of classroom climate," The fournal of Creative Behavior, vol. 32, no. 4, pp. 258-277, 1998.

[54] J. A. Plucker and R. A. Beghetto, "Why not be creative when we enhance creativity," Rethinking gifted education, pp. 215-226, 2003. 
[55] M. Resnick and B. Silverman, "Some reflections on designing construction kits for kids," in Proceedings of the 2005 conference on Interaction design and children. ACM, 2005, pp. 117-122.

[56] A. Cropley, "In praise of convergent thinking," Creativity research journal, vol. 18 no. 3, pp. 391-404, 2006.

[57] J. Piaget, "The theory of stages in cognitive development." 1971.

[58] K. C. Krafft and L. E. Berk, "Private speech in two preschools: Significance of open-ended activities and make-believe play for verbal self-regulation," Early Childhood Research Quarterly, vol. 13, no. 4, pp. 637-658, 1998.

[59] B. van Hoeve, L. De Valk, and T. Bekker, "Toinggg: How changes in children's activity level influence creativity in open-ended play," in International Conference on Advances in Computer Entertainment Technology. Springer, 2013, pp. 642645.

[60] F. Kaplan, "Everyday robotics: robots as everyday objects," in Proceedings of the 2005 joint conference on Smart objects and ambient intelligence: innovative context-aware services: usages and technologies, 2005, pp. 59-64.

[61] E. Cha, A. D. Dragan, and S. S. Srinivasa, "Perceived robot capability," in 2015 24th IEEE International Symposium on Robot and Human Interactive Communication (RO-MAN). IEEE, 2015, pp. 541-548.

[62] J.-g. Choi and M. Kim, "The usage and evaluation of anthropomorphic form in robot design," 2009.

[63] R. Zaporah, Action theater: The improvisation of presence. North Atlantic Books, 1995.

[64] P. Alves-Oliveira, "Boosting children's creativity through creative interactions with social robots," Ph.D. dissertation, Iscte-iul, 2020.

[65] D. Moher, L. Shamseer, M. Clarke, D. Ghersi, A. Liberati, M. Petticrew, P. Shekelle, and L. A. Stewart, "Preferred reporting items for systematic review and metaanalysis protocols (prisma-p) 2015 statement," Systematic reviews, vol. 4, no. 1 p. $1,2015$.

[66] C. F. Justo, "Creative relaxation, motor creativity, self-concept in a sample of children from early childhood education," Electronic fournal of Research in Educational Psychology, vol. 6, no. 1, pp. 29-50, 2008.

[67] P. T. Sowden, L. Clements, C. Redlich, and C. Lewis, "Improvisation facilitates divergent thinking and creativity: Realizing a benefit of primary school arts education." Psychology of Aesthetics, Creativity, and the Arts, vol. 9, no. 2, p. 128, 2015.

[68] M. Moore and S. W. Russ, "Follow-up of a pretend play intervention: Effects on play, creativity, and emotional processes in children," Creativity Research fournal, vol. 20, no. 4, pp. 427-436, 2008.

[69] D. H. Clements, "Enhancement of creativity in computer environments," American Educational Research fournal, vol. 28, no. 1, pp. 173-187, 1991.

[70] G. Gordon, C. Breazeal, and S. Engel, "Can children catch curiosity from a social robot?" in Proceedings of the Tenth Annual ACM/IEEE International Conference on Human-Robot Interaction. ACM, 2015, pp. 91-98.

[71] G. F. Smith, "Idea-generation techniques: A formulary of active ingredients," The fournal of Creative Behavior, vol. 32, no. 2, pp. 107-134, 1998.

[72] T. I. Lubart, "Models of the creative process: Past, present and future," Creativity research journal, vol. 13, no. 3-4, pp. 295-308, 2001.

[73] P. Alves-Oliveira, P. Arriaga, A. Paiva, and G. Hoffman, "Yolo, a robot for creativity: A co-design study with children," in Proceedings of the 2017 Conference on Interaction Design and Children, 2017, pp. 423-429.

[74] G. J. Feist, "A meta-analysis of personality in scientific and artistic creativity," Personality and social psychology review, vol. 2, no. 4, pp. 290-309, 1998.

[75] M. Batey and A. Furnham, "Creativity, intelligence, and personality: A critical review of the scattered literature," Genetic, social, and general psychology monographs, vol. 132, no. 4, pp. 355-429, 2006.

[76] P. Alves-Oliveira, P. Arriaga, G. Hoffman, and A. Paiva, "Representation of movement for robots with personality: A co-design study with small groups of children," in Proc. 26th IEEE Int. Symp. Robot and Human Interactive Communication (RO-MAN 2017), 2017.
[77] D. Schleicher, P. Jones, and O. Kachur, "Bodystorming as embodied designing," Interactions, vol. 17, no. 6, pp. 47-51, 2010.

[78] I. E. Van Kesteren, M. M. Bekker, A. P. Vermeeren, and P. A. Lloyd, “Assessing usability evaluation methods on their effectiveness to elicit verbal comments from children subjects," in Proceedings of the 2003 conference on Interaction design and children. ACM, 2003, pp. 41-49.

[79] P. Alves-Oliveira, S. Gomes, A. Chandak, P. Arriaga, G. Hoffman, and A. Paiva, "Software architecture for yolo, a creativity-stimulating robot," SoftwareX, vol. 11, p. 100461, 2020.

[80] J. M. Morse, "The significance of saturation," 1995.

[81] B. G. Glaser, A. L. Strauss, and E. Strutzel, "The discovery of grounded theory; strategies for qualitative research," Nursing research, vol. 17, no. 4, p. 364, 1968.

[82] P. Alves-Oliveira, P. Arriaga, A. Paiva, and G. Hoffman, "Guide to build yolo, a creativity-stimulating robot for children," HardwareX, vol. 6, p. e00074, 2019.

[83] E. P. Torrance, Torrance tests of creative thinking: Norms-technical manual: Verbal tests, forms $a$ and $b$ : Figural tests, forms $a$ and $b$. Personal Press, Incorporated, 1966.

[84] R. J. Sternberg, "Creativity or creativities?" International fournal of HumanComputer Studies, vol. 63, no. 4-5, pp. 370-382, 2005.

[85] J. P. Guilford, "The nature of human intelligence." 1967.

[86] P. Alves-Oliveira, P. Arriaga, M. A. Cronin, and A. Paiva, "Creativity encounters between children and robots," in Proceedings of the 2020 ACM/IEEE International Conference on Human-Robot Interaction, 2020, pp. 379-388.

[87] L. S. Vygotsky, "Play and its role in the mental development of the child," Soviet psychology, vol. 5, no. 3, pp. 6-18, 1967.

[88] E. T. Ortlieb, "The pursuit of play within the curriculum." fournal of Instructional Psychology, vol. 37, no. 3, 2010.

[89] J. Piaget, Play, dreams and imitation in childhood. Routledge, 1945.

[90] J. Moyles, The excellence of play. McGraw-Hill Education (UK), 2014.

[91] D. Whitebread, D. Neale, H. Jensen, C. Liu, L. Solis, E. Hopkins, K. Hirsh-Pasek, and J. Zosh, "The role of play in children's development: a review of the evidence," The LEGO Foundation, pp. 1-40, 2017.

[92] J. Piaget, "The stages of the intellectual development of the child," Educational psychology in context: Readings for future teachers, pp. 98-106, 1965.

[93] N. Brosterman and K. Togashi, Inventing kindergarten. HN Abrams New York, 1997.

[94] M. Montessori, The montessori method. Transaction publishers, 2013.

[95] J. L. Frost, Play and playscapes. Delmar Albany, NY, 1992.

[96] J. G. Brown and C. Burger, "Playground designs and preschool children's behaviors," Environment and behavior, vol. 16, no. 5, pp. 599-626, 1984

[97] G. T. Moore and U. Cohen, "Exceptional education and the physical environment: Toward behaviorally-based design principles." 1978.

[98] S. Barab, Design-Based Research: A Methodological Toolkit for the Learning Scientist. Cambridge University Press, 2006.

[99] J. C. Read, M. Horton, G. Sim, P. Gregory, D. Fitton, and B. Cassidy, "Check: a tool to inform and encourage ethical practice in participatory design with children," in CHI'13 Extended Abstracts on Human Factors in Computing Systems. ACM, 2013, pp. 187-192.

[100] M. Van Mechelen, G. Sim, B. Zaman, P. Gregory, K. Slegers, and M. Horton, "Applying the check tool to participatory design sessions with children," in Proceedings of the 2014 conference on Interaction design and children. ACM, 2014, pp. 253-256.

[101] J. C. Read, "Validating the fun toolkit: an instrument for measuring children's opinions of technology," Cognition, Technology \& Work, vol. 10, no. 2, pp. 119-128, 2008.

[102] N. Hazel, "Elicitation techniques with young people," Social research update, vol. 12 , no. 4 , pp. $1-8,1995$.

[103] F. Gibson, "Conducting focus groups with children and young people: strategies for success," Fournal of research in nursing, vol. 12, no. 5, pp. 473-483, 2007. 